\title{
Psychological Impacts of COVID-19 Pandemic on the Brazilian Population: Occupational Analysis
}

\author{
Lucas Emmanuel Pedro de Paiva Teixeira1 ${ }^{*}$, Renato Leonardo de Freitas ${ }^{2,3,4}$, Alberto Abad ${ }^{5}$, \\ Juliana Almeida da Silva ${ }^{2,6}$, Mayra Antonelli-Ponti7 , Cláudia Helena Cerqueira Mármora ${ }^{8}$, \\ Luis Antonio Monteiro Camposs ${ }^{9}$, Scheila Paiva ${ }^{10}$, Sandra Bastos ${ }^{11}$, José Aparecido Da Silva ${ }^{12}$
}

${ }^{1}$ Institute of Motricity Sciences, Federal University of Alfenas (UNIFAL-MG), Alfenas, Brazil

${ }^{2}$ Behavioural Neurosciences Institute (INeC), Ribeirão Preto, Brazil

${ }^{3}$ Biomedical Sciences Institute, Federal University of Alfenas (UNIFAL), Alfenas, Brazil

${ }^{4}$ Laboratory of Neurosciences of Pain \& Emotions and Multi-User Centre of Neuroelectrophysiology,

Department of Surgery and Anatomy, Ribeirão Preto Medical School of the University of São Paulo, Ribeirão Preto, Brazil.

${ }^{5}$ Psychology Graduate Program, Federal University of Juiz de Fora (UFJF), Juiz de Fora, Brazil

${ }^{6}$ Laboratory of Neuroanatomy and Neuropsychobiology, Department of Pharmacology,

Ribeirão Preto Medical School of the University of São Paulo (FMRP-USP), Ribeirão Preto, Brazil

${ }^{7}$ Laboratory of Studies and Research in Social Economy, University of São Paulo at Ribeirão Preto, Ribeirão Preto, Brazil

${ }^{8}$ Department of the Old, Adult and Maternal-infant, School of Physical Therapy, Graduate Program in Psychology,

Federal University of Juiz de Fora (UFJF), Juiz de Fora, Brazil

${ }^{9}$ Master's Program in Psychology, Catholic University of Petrópolis, Petrópolis, Brazil. Department of Psychology,

Pontifical Catholic University of Rio de Janeiro, Rio de Janeiro, Brazil

${ }^{10}$ Psychology Graduate Program, Federal University of Juiz de Fora (UFJF), Juiz de Fora, Brazil.

${ }^{11}$ Otorhinolaryngology Institute (ISBO), São Paulo, Brazil

${ }^{12}$ Laboratory of Psychophysics, Perception, Psychometrics, and Pain, University of São Paulo at Ribeirão Preto, Ribeirão Preto, Brazil

Email: *lucas.teixeira@unifal-mg.edu.br

How to cite this paper: Teixeira, L.E.P.P., de Freitas, R.L., Abad, A., da Silva, J.A., Antonelli-Ponti, M., Mármora, C.H.C., Campos, L.A.M., Paiva, S., Bastos, S. and Da Silva, J.A. (2021) Psychological Impacts of COVID-19 Pandemic on the Brazilian Population: Occupational Analysis. World Journal of Neuroscience, 11, 145-160. https://doi.org/10.4236/wjns.2021.112013

Received: April 13, 2021

Accepted: May 28, 2021

Published: May 31, 2021

\begin{abstract}
Context and objectives: The unexpected pandemic caused by the severe acute respiratory syndrome coronavirus 2 (SARS-CoV-2) affected several activities and exposed workers, students and the large mass of unemployed people to an economic and psychological pressure that could lead to various problems, such as anxiety, fear, depression and insomnia, consequently causing impairment of quality of life. Method: A cross-sectional study was conducted using the COVID-19 Peri-Traumatic Distress Index (CPDI) and the Fear of COVID-19 Scale (FCV-19S) to measure peri-traumatic stress and fear, such as psychological reactions during the 2019 coronavirus disease (COVID-19) pandemic. An online spreadsheet was used as a data collection tool to send the questionnaire and scales to a sample of 1,844 participants. Data were analyzed in groups of health professionals, students and teachers,
\end{abstract}


Copyright ( 2021 by author(s) and Scientific Research Publishing Inc. This work is licensed under the Creative Commons Attribution International License (CC BY 4.0).

http://creativecommons.org/licenses/by/4.0/

Open Access and an analysis was performed between unemployed and employed people in order to evaluate the impact of employment on the population's mental health. Results: All groups presented from moderate to high CPDI and FCV-19S scores, and students and unemployed people had higher levels of stress and fear. Conclusion: COVID-19 pandemic had a significant impact on the Brazilian population, with students and the unemployed showing the highest rates of stress and fear.

\section{Keywords}

Mental Health, Fear, Peri-Traumatic Stress, COVID-19, Student, Unemployed

\section{Introduction}

In December 2019, a new coronavirus denominated Severe Acute Respiratory Syndrome Coronavirus 2 (SARS-CoV-2 or 2019-nCoV) of unknown origin was spread in Hubei Province, China. The epidemic disease caused by SARS-CoV-2 was called 2019 coronavirus disease (COVID-19). COVID-19 manifested its several symptoms from asymptomatic and mild symptoms to severe illness and death. The viral infection has expanded internationally and the World Health Organization (WHO) announced a Public Health Emergency of International Concern [1]. On December 7, 2020, the number of confirmed cases worldwide exceeded 67 million, with more than one and a half million deaths [2].

Although global attention is mainly focused on the effects of coronavirus on physical health, its impacts on psychological health cannot be overlooked [3]. The outbreak itself and the measures taken to control it have been probably highly stressful for many individuals. Abad and collaborators (2020) showed that COVID-19 started in China and reached the world becoming a pandemic, arriving in Latin America in mid-February 2020. The South American continent is experiencing a delicate political, economic and social moment that reflects the fragility of our health and science systems and of the strategies to reduce contagion rates, overloading health services. Nevertheless, several studies are being conducted in Brazil and worldwide aiming to understand the characteristics of the disease and the cure of people infected by this coronavirus [4].

There is a great deal of literature on the closure of educational institutions to reduce the spread of infectious diseases in the community, breaking important transmission chains [5].

According to UNESCO (2020), most governments around the world have temporarily closed educational institutions in attempt to contain the spread of the COVID-19 pandemic. These nationwide closures are affecting hundreds of millions of students. Several other countries have implemented localized closures impacting millions of additional students, and in Brazil alone there are more than 52 million impacted students. This also had a strong impact on the students' teachers and parents [6] [7]. 
This closure of educational institutions during the COVID-19 pandemic could have a serious impact on the careers of 2020 college graduates. They are going through major interruptions in teaching and evaluation, especially for those who are in the final stage for graduation. They will probably graduate late due to the postponement of the last semesters of their degrees. In addition, graduates will face serious challenges because of the global recession caused by the COVID-19 crisis [5].

COVID-19 pandemic, as well as measures of isolation and social distancing, highlighted our already pre-existing contradictions and inequalities. The legion of informal Brazilian workers gained visibility with the 107 million requests for the emergency aid. The spread of contamination, illness and deaths to the peripheries of large urban centers demonstrated the ineffectiveness of the requirement of social isolation in the absence of effective public policies that would guarantee the urgency of immediate survival. Informality already affects about $40 \%$ of the Brazilian workforce (IBGE, 2020). Unemployment and the loss of rights have spread intensely amid the situation of "public health emergency", projecting a dramatic future for those whose living depends on their work [8].

The global economy instability caused by COVID-19 has resulted in the loss of access to employment for millions of people. As a result, these same individuals will face the pain of job loss in the present and the stress of job searching process in the future. In mass unemployment circumstances, where competition for jobs tends to be excessively high, the likelihood of negative job-seeking experiences (e.g. failed interviews) certainly increases. The unemployed who continue to seek employment without success cause themselves additional problems or even abandon the job search. For those who remain unemployed for a substantial period, the risks for alcohol abuse, depression and anxiety increase [9].

In recent decades, institutional and social expectations regarding teaching have increased. The understanding of the impacts these marked changes cause on teachers' health is part of the broader context of workers' health studies. This field has revealed the components of a scenario marked by the precarious-ization of work in general and its deleterious consequences on workers' health, especially in teachers [10].

On the other hand, health professionals are comprised by those who have focused their work on ventilators and intensive care beds, while others remained at the forefront of the treatment of other health conditions. Evidence from disease epidemics shows that health professionals are at risk of developing mental health conditions in the short and long term. The WHO warned about the potential negative impact of the COVID-19 crisis on the mental well-being of health and social care professionals [11].

In summary, in a pandemic of proportions never before seen in Brazil as we are facing now, it is important to investigate its psychological impact on real populations so that health authorities can develop strategies to reduce psychological symptoms in a targeted way to the most vulnerable population [12]. 
Therefore, it is necessary to evaluate the psychological impacts of COVID-19 in different population groups, because the type and level of occupation are important variables to understand the reality and develop public policies addressing these issues.

\section{Methods}

A cross-sectional study was conducted from April 12th to 18th 2020 using the COVID-19 Peri-Traumatic Distress Index (CPDI) (Appendix 1) and the Fear of COVID-19 Scale (FCV-19S) (Appendix 2) to measure peri-traumatic stress and fear as psychological reactions during the COVID-19 pandemic. To do so, an online spreadsheet was used as a data collection instrument to send the questionnaire and scales to a sample of 1844 participants over 18 years of age, living in Brazil. The volunteers were selected by a non-probabilistic sample, through social networks, e-mail and messages via cell phone applications.

First, the participants answered a sociodemographic survey that included specific questions about the prevalence of chronic diseases and levels of social isolation during the COVID-19 pandemic, as well as their occupation during the pandemic. Next, we evaluated distress through CPDI, elaborated as a self-report questionnaire that measures depression, anxiety, avoidance, compulsive behavior, specific phobias, cognitive changes, physical symptoms and loss of functional social coexistence. The content of the CPDI questionnaire was validated by Qiu et al. (2020) and the twenty-four questions were presented in Likert format in five categories of answers (never, occasionally, sometimes, frequently, and most of the time). We measured fear with the FCV-19S, presented in Likert format in five categories of answers (strongly disagree, disagree, neither agree nor disagree, agree, and strongly agree). It consists in a one-dimensional scale of seven items with robust, reliable and valid psychometric properties for the evaluation and relief of COVID-19 fear [13]. Regarding statistical analyses, data are presented as median, $25^{\text {th }}$ to $75^{\text {th }}$ percentiles. The reliability of the two scales was evaluated by calculating Cronbach's Alpha, Bartlett's test of Sphericity and the Kaiser-Meyer-Olkin (KMO) adequacy index. Then, Shapiro-Wilk normality test was performed to verify the normal distribution of all data. Data on the scale of fear and peri-traumatic suffering were submitted to a one-way repeated measures variance analysis (ANOVA split-plot), followed by Tukey's post hoc test when appropriate. This research was approved by the National Research Ethics Commission-CONEP, Brazil.

\section{Results}

First, Table 1 shows the characterization of the sample for the analyzed data, where the proportion of interviewees who had a health problem, who had health insurance, who had employment, and the proportion by gender and by age group were analyzed. Out of the sample, 643 participants (34.9\%) declared chronic disease prevalence, standing out suffering, or psychologlical disorder 
indicators (16.1\%). Based on results, it is possible to build a rough profile of the participants: single (48.7\%) woman (79.8\%), with an average of 36.2 years of age, with up to one child $(75.7 \%)$, with a college degree (complete or incomplete $89.7 \%)$, working $(69.5 \%)$ with health insurance $(69.4 \%)$ and in social isolation during the pandemic $(87.0 \%)$.

Next, Table 2 presents the means, confidence intervals, weighted means and

Table 1. Descriptive table to characterize the sample, proportion of respondents who have a health problem, proportion who have a health plan, proportion by gender, proportion that has a job and proportion by age group.

\begin{tabular}{|c|c|c|c|}
\hline Variable & class & Proportion (\%) & $\begin{array}{l}\text { Proportion Confidence } \\
\text { Interval (CI) - } 95 \%\end{array}$ \\
\hline \multirow{3}{*}{ Have a health problem } & Not & 65.40 & $63.17-67.57$ \\
\hline & Yes & 34.60 & $32.43-36.83$ \\
\hline & TOTAL & 100.00 & - \\
\hline \multirow{3}{*}{ Has a health plan } & Not & 30.69 & $28.60-32.87$ \\
\hline & Yes & 69.31 & $67.13-71.40$ \\
\hline & TOTAL & 100.0 & - \\
\hline \multirow{3}{*}{ Gender } & Female & 79.77 & $77.85-81.57$ \\
\hline & Male & 19.96 & $18.17-21.87$ \\
\hline & TOTAL & 99.73 & - \\
\hline \multirow{3}{*}{ Has a job } & Not & 30.53 & $28.45-32.70$ \\
\hline & Yes & 69.47 & $67.30-71.55$ \\
\hline & TOTAL & 100.00 & - \\
\hline \multirow{4}{*}{ Age range } & Less than 25 & 21.20 & $19.37-23.16$ \\
\hline & 26 to 50 years & 63.07 & $60.81-65.27$ \\
\hline & 51 or more & 15.73 & $14.11-17.49$ \\
\hline & TOTAL & 100.00 & - \\
\hline
\end{tabular}

Note. Presents a comparison of the sociodemographic data between the groups using media and standard deviation.

Table 2. Cronbach's Alpha: Mean and confidence interval by factor-CPDI and fear scales.

\begin{tabular}{ccccccccc}
\hline Class & Minimum & Maximum & Median & $\begin{array}{c}\text { Simple } \\
\text { Average }\end{array}$ & $\begin{array}{c}\text { Weighted } \\
\text { average }\end{array}$ & $\begin{array}{c}\text { Confidence } \\
\text { Interval (95\%) }\end{array}$ & $\begin{array}{c}\text { Standard } \\
\text { deviation }\end{array}$ & $\begin{array}{c}\text { Cronbach's } \\
\text { alpha }\end{array}$ \\
\hline CPDI Fator 1 & 0.00 & 4.00 & 2.00 & 1.99 & 1.99 & $1.95-2.03$ & 1.0 & 0.74 \\
CPDI Fator 2 & 0.00 & 3.57 & 1.14 & 1.16 & 1.17 & $1.14-1.20$ & 0.61 & 0.63 \\
CPDI Fator 3 & 0.00 & 4.00 & 1.86 & 1.90 & 1.87 & $1.85-1.94$ & 0.92 & 0.83 \\
CPDI Fator 4 & 0.00 & 4.00 & 0.60 & 0.83 & 0.83 & $0.79-0.87$ & 0.85 & 0.77 \\
Total CPDI & 4.00 & 93.00 & 38.00 & 39.57 & 39.57 & $38.83-40.31$ & 16.24 & 0.90 \\
Fear Score & 7.00 & 35.00 & 17.00 & 18.08 & 1.99 & $17.78-18.39$ & 6.69 & 0.88 \\
\hline
\end{tabular}

Note. Shows the means, confidence intervals, weighted means and Cronbach's Alpha estimate for each of the factors of the respective CPDI scales and Fear scale. 
Cronbach's Alpha estimate for each one of the factors of the CPDI and Fear scale, respectively. CPDI is composed of four factors, as well as the Fear scale, which is one-dimensional and the Fear Score Mean was used for the exposed calculations. Regarding Cronbach's Alpha, the total factors of the CPDI and the Fear scale had the highest internal consistencies, being 0.90 and 0.88 , respectively. For an exploratory factor analysis, Bartlett's Sphericity test was applied and it shows that the variables observed by the questionnaire are correlated in the population in both scales for $\mathrm{p} \leq 0.00$. Finally, the KMO sample size adequacy factor shows that the sample size is adequate to test the variables, with all CPDI values being $\geq 0.82$, except question 21 (0.57) and all values of the Fear scale being $\geq 0.84$.

Table 3 shows the CPDI scores, where we can find the lowest mean value of 37.88 for health professionals and the highest value of 43.29 for students. The students' scores are statically significant (p-value $\leq 0.05$ ) when compared to all other groups. Unemployed individuals showed higher stress levels than the employed ( $p$-value $\leq 0.001$ ), while those with health insurance had higher values than those without health insurance, although the difference was not statistically significant.

Table 4 shows that all individuals have scores of moderate level of fear of COVID-19, and the patterns are similar to those of stress shown by CPDI, with students, the unemployed and other categories having higher score levels, without statistical difference though.

Table 5 shows the analysis according to age groups, and it indicates that all individuals present scores of moderate levels of stress and fear of COVID-19. The highest score in CPDI was the students', while in the Fear scale, the highest scores were those from the group of people aged 51 years or more. It is worth noting that the number of people aged 25 years or less coincides with the number of students, which psychometrically is a good indicative of data consistency,

Table 3. Peri-traumatic distress scale (CPDI).

\begin{tabular}{|c|c|c|c|c|c|c|c|c|c|}
\hline Variable & Class & Average & $\begin{array}{c}\text { Confidence } \\
\text { Interval (95\%) }\end{array}$ & $\begin{array}{c}\text { Minimum } \\
\text { value }\end{array}$ & $\begin{array}{c}1^{\text {st }} \\
\text { quartile }\end{array}$ & Median & $\begin{array}{c}3^{\text {rd }} \\
\text { quartile }\end{array}$ & $\begin{array}{l}\text { Maximum } \\
\text { value }\end{array}$ & $P$-value \\
\hline \multirow{2}{*}{ CPDI Score } & Unemployed & 41.60 & $40.23-42.98$ & 4.00 & 29.00 & 41.00 & 54.00 & 91.00 & 0.00 \\
\hline & Employee & 38.68 & $37.81-39.56$ & 8.00 & 26.00 & 38.00 & 50.00 & 93.00 & \\
\hline \multirow{2}{*}{ CPDI Score } & Without health insurance & 40.74 & $39.36-42.17$ & 4.00 & 27.00 & 39.00 & 53.75 & 92.00 & 0.08 \\
\hline & With health plan & 39.05 & $38.18-39.92$ & 8.00 & 27.00 & 38.00 & 51.00 & 93.00 & \\
\hline \multirow{2}{*}{ CPDI Score } & Profissionais da insurance & 37.88 & $36.51-39.26$ & 10.00 & 25.00 & 36.00 & 48.00 & 93.00 & 0.05 \\
\hline & Other categories & 40.18 & $39.30-41.05$ & 4.00 & 27.00 & 39.00 & 53.00 & 91.00 & \\
\hline \multirow{2}{*}{ CPDI Score } & Professor & 37.34 & $35.34-39.34$ & 9.00 & 27.00 & 35.00 & 47.25 & 82.00 & 0.01 \\
\hline & Other categories & 39.88 & $39.08-40.67$ & 4.00 & 27.00 & 39.00 & 52.00 & 93.00 & \\
\hline \multirow{2}{*}{ CPDI Score } & Student & 43.29 & $41.56-45.01$ & 4.00 & 30.00 & 43.00 & 56.00 & 84.00 & 0.00 \\
\hline & Non-student & 38.74 & $37.93-39.56$ & 8.00 & 26.00 & 37.00 & 50.50 & 93.00 & \\
\hline
\end{tabular}

Note. Compares the symptoms of stress and anxiety caused by COVID-19, between the groups. Student's t-test was used for parametric variables and the Mann-Whitney test for non-parametric variables. $\mathrm{CI}=95 \%$ 
Table 4. Fear scale score-FEAR Score.

\begin{tabular}{|c|c|c|c|c|c|c|c|c|c|}
\hline Variable & Class & Average & $\begin{array}{c}\text { Confidence } \\
\text { Interval (95\%) }\end{array}$ & $\begin{array}{l}\text { Minimum } \\
\text { value }\end{array}$ & $1^{\text {st }}$ quartile & Median & $3^{\text {rd }}$ quartile & $\begin{array}{l}\text { Maximum } \\
\text { value }\end{array}$ & P-value \\
\hline \multirow{2}{*}{ Fear Score } & Unemployed & 18.28 & $17.71-18.85$ & 7.00 & 13.00 & 18.00 & 23.00 & 35.00 & 0.43 \\
\hline & Employee & 18.00 & $17.64-18.36$ & 7.00 & 13.00 & 17.00 & 23.00 & 35.00 & \\
\hline \multirow{2}{*}{ Fear Score } & Without health insurance & 18.02 & $17.44-18.60$ & 7.00 & 13.00 & 17.00 & 23.00 & 35.00 & 0.68 \\
\hline & With health plan & 18.11 & $17.75-18.47$ & 7.00 & 13.00 & 18.00 & 23.00 & 35.00 & \\
\hline \multirow{2}{*}{ Fear Score } & Profissionais da insurance & 17.67 & $17.12-18.23$ & 7.00 & 13.00 & 17.00 & 22.00 & 35.00 & 0.95 \\
\hline & Other categories & 18.23 & $17.87-18.59$ & 7.00 & 13.00 & 18.00 & 23.00 & 35.00 & \\
\hline \multirow{2}{*}{ Fear Score } & Professor & 18.00 & $17.17-18.83$ & 7.00 & 13.00 & 18.00 & 23.00 & 35.00 & 0.22 \\
\hline & Other categories & 18.09 & $17.77-18.42$ & 7.00 & 13.00 & 17.00 & 23.00 & 35.00 & \\
\hline \multirow{2}{*}{ Fear Score } & Student & 17.52 & $16.81-18.23$ & 7.00 & 12.00 & 17.00 & 22.00 & 35.00 & 0.11 \\
\hline & Non-student & 18.21 & $17.87-18.55$ & 7.00 & 13.00 & 18.00 & 23.00 & 35.00 & \\
\hline
\end{tabular}

Note. It presents a comparison of the COVID-19 fear symptoms between the groups. Student's t-test was used for parametric variables and the Mann-Whitney test for non-parametric variables. $\mathrm{CI}=95 \%$.

Table 5. CPDI and fear score by age group.

\begin{tabular}{|c|c|c|c|c|c|c|c|c|}
\hline Variable & Class & Average & $\begin{array}{c}\text { Confidence } \\
\text { Interval (95\%) }\end{array}$ & $\begin{array}{l}\text { Minimum } \\
\text { value }\end{array}$ & $1^{\text {st }}$ quartile & Median & $3^{\text {rd }}$ quartile & $\begin{array}{c}\text { Maximum } \\
\text { value }\end{array}$ \\
\hline \multirow{3}{*}{ CPDI Score } & Less than 25 & 43.45 & $42.00-44.90$ & 10.00 & 31.00 & 43.00 & 56.00 & 79.00 \\
\hline & 26 to 50 years & 39.79 & $38.83-40.75$ & 4.00 & 27.00 & 39.00 & 52.00 & 93.00 \\
\hline & 51 or more & 32.80 & $31.08-34.52$ & 11.00 & 21.00 & 30.00 & 41.00 & 91.00 \\
\hline \multirow{3}{*}{ Fear Score } & Less than 25 & 17.75 & $17.16-18.35$ & 7.00 & 13.00 & 17.00 & 22.00 & 35.00 \\
\hline & 26 to 50 years & 17.37 & $16.63-18.11$ & 7.00 & 12.25 & 17.00 & 22.00 & 35.00 \\
\hline & 51 or more & 18.40 & $18.00-18.81$ & 7.00 & 13.00 & 18.00 & 23.00 & 35.00 \\
\hline
\end{tabular}

Table 6. Tukey test with interactions between age groups-CPDI Scores.

\begin{tabular}{ccc}
\hline Age groups & Difference & P-value \\
\hline 51 years or more: 26 to 50 years & -6.99 & 0.001 \\
25 years or less: 26 to 50 years & 3.66 & 0.001 \\
25 years or less: 51 or more & 1065 & 0.001 \\
\hline
\end{tabular}

because it is in this age group in which most students are concentrated.

In addition, Table 6 shows that all individuals have CPDI scores at moderate levels of stress and anxiety, and the score of volunteers aged 25 years or less was statistically higher than those from other groups. Moreover, the group of volunteers aged between 26 and 50 years had higher scores than the group of volunteers aged 51 years or more.

In addition, shows that all individuals have CPDI scores at moderate levels of stress and anxiety, and the score of volunteers aged 25 years or less was statistically higher than those from other groups. Moreover, the group of volunteers aged between 26 and 50 years had higher scores than the group of volunteers 
Table 7. Tukey test with interactions between age groups-Fear Scores.

\begin{tabular}{ccc}
\hline Age groups & Difference & P-value \\
\hline 51 years or more: 26 to 50 years & -1.03 & 0.05 \\
25 years or less: 26 to 50 years & -0.65 & 0.19 \\
25 years or less: 51 or more & 0.38 & 0.73 \\
\hline
\end{tabular}

aged 51 years or more. Lastly, Table 7 shows that all individuals have scores of moderate levels of fear of COVID-19, and in our study, the only group that presented statistically higher levels than the others was the group of people aged 51 years or older.

\section{Discussion}

Maslow first postulated in his seminal 1943 article, and later in 1958, "A Dynamic Theory of Human Motivation" which describes a set of basic human needs that are organized into a hierarchy of relative predominance. Maslow believed that human needs are organized in hierarchies of prepotency (i.e., predominance) and that the emergence of a need usually depends on the prior satisfaction of another more prepotent need. In Maslow's opinion, the hierarchy of needs is organized as follows: 1) Physiological needs; 2) Safety needs; 3) Love and belonging needs; 4) Esteem needs; and 5) Self-actualization needs. In addition, people are motivated by the desire to achieve or maintain the various conditions on which these basic satisfactions are set, and by certain more intellectual desires. Any impediment or possibility of thwarting these basic human objectives, or any danger to the defenses that protect them or the conditions on which they are set are considered psychological threats [14]. COVID-19 threatens all layers of Maslow's hierarchy, and deficits in each of these basic needs have deleterious consequences for our mental health [15].

In a study that evaluated 45,161 participants recruited by chain sampling, $\mathrm{Al}$ meida et al. (2020) report that approximately $74 \%$ of Brazilians adhered to social restriction. Regarding flu symptoms, $28.1 \%$ reported having presented some symptom, but only $5.9 \%$ tested for COVID-19. Regarding the socioeconomic situation, $55.1 \%$ reported a decrease in family income and 7.0\% lost all income; $25.8 \%$ of the individuals could not work, and the group of informal workers was the most affected (50.6\%). Regarding health conditions, $29.4 \%$ noticed that their health worsened, $45 \%$ had sleep problems, $40 \%$ often had feelings of sadness and $52.5 \%$ had anxiety/nervousness; $21.7 \%$ sought health services, and among these, $13.9 \%$ could not get health care [16]. Considering this perspective, we observed in our study similar conditions, such as high levels of stress, fear and anxiety, including those related to work. In the present study, despite the higher rates in volunteers without health insurance, they were not statistically significant. However, the lack of specialized medical care and the uncertainty of receiving adequate care may have influenced the high levels of anxiety, stress and fear in the group of people who do not have health insurance, since studies point to a higher 
mortality rate in public hospitals ICUs when compared to private hospitals.

During the pandemic, people live daily with the possibility of their lives and loved ones being harmed by the virus. However, the disease is not the only traumatic factor. Economic instability generated by financial crises can increase economic stress related to employment (i.e., job insecurity) and income (i.e., financial stress). In this context, the economic shock imposed by the response to the pandemic is projected to exceed the one caused by the global financial crisis of 2007-2008 and threatens to be a recession as great as any other since the 1930s.

From a psychological perspective, the human costs of this reality are probably substantial. Besides the utilitarian aspect of compensation, humans are known to derive significant meanings and values from their work. Indeed, a research found that work is experienced as a source of reflection of values and expression of personal beliefs that people consider inextricable from their self-concept [18].

Therefore, long-term isolation in conjunction with loss of employment or income can produce adverse effects on the mental well-being and quality of life of individuals [19], which can be observed in our results, where unemployed individuals had higher levels of stress, anxiety and fear.

These results can be compared with the data found by Ma et al. (2020), where participants who had a part-time job were significantly more likely to experience greater financial and household stress and feel apprehensive due to the COVID-19 pandemic after the reopening of Wuhan city in China, than participants who had full-time jobs or were students [20].

Another factor related to work that could be a source of psychological distress is work search. It was evaluated by Sun et al. (2013) in a sample of 184 newly graduated university students who provided monthly reports of their job search activities over a period of 8 months [21]. They found that the amount of job offers and the effort to seek employment were inversely proportional, which may justify the high level of dismay during the pandemic. In this context, it is assumed that the first signs of deterioration of the national labor market may come from an increase in the dismayed population, i.e., people who would like to work, but for some reason do not perform an effective search for work [22].

With regard to the categories of workers, two categories have had special attention in research because their professions are related to the pandemic or are directly affected by it. In our study, teachers and health professionals were prevalent in the sample and both presented high levels of stress and fear. However, unlike other studies, these two groups of professionals presented similar scores among themselves and, although considered worrying, they were lower than the stress and fear scores of other professionals. Our data regarding health professionals corroborate those found by Mrklas et al. (2020), where self-reported symptoms of moderate or high stress, anxiety and depression were all statistically and significantly higher in other workers than in health professionals $(\mathrm{P}<$ 0.001). In the same comparison, "other workers" reported higher obses- 
sive-compulsive symptoms (concern with contamination and compulsive behavior of washing hands) after the onset of the pandemic $(P<0.001)[23]$.

Perhaps these data are justified by a better adaptation of health professionals and teachers to a pandemic and its effects, but it is not clear to what extent this adaptive behavior of health professionals or other workers influences perception and coping with the pandemic.

In relation to teachers, a survey evaluated the behavior of English teachers during the first six weeks of the pandemic, when they were asked to describe a low point, a high point and a tipping point [24]. The six most cited themes by teachers were uncertainty, finding a way, concern about the vulnerable, importance of relationships, teacher identity and reflections. This study states that the teachers' narratives suggest that, after an initial period of uncertainty, they settled into the situation and found a way forward, supported by strong relationships. However, they remain extremely concerned about the most vulnerable students and want a more integrated government thinking on how to support them effectively, along with the clarity of policymakers to enable future planning.

The high prevalence of psychological symptoms in undergraduate students has been frequently pointed out [25] [26]. At this time, undergraduate students experience anguish generated by the uncertainty and abrupt interruption of the semester in addition to the anxiety caused by the closure of universities. As more universities are transitioning to remote education, some students suffer from mental health problems due to the disruption of academic routine. Many students have to interrupt their research projects and internships when universities evacuate them from campus [27]. In addition, these interruptions in their research projects and internships affect their study program, delay their graduation and impair their competitiveness in the labor market, which, in turn, fuels anxiety among undergraduate students. They may also struggle with the cost of returning home and managing their belongings [28].

In this context, healthy young people who, at some level, may have not noticed the physical consequences of the infection, now see their existential interests economically threatened as well.

In a study that assessed the initial psychological responses of the members of the University of Valladolid in Spain to COVID-19, depression, anxiety and stress were evaluated and measured by DASS-21. Regarding the different groups at the university, significantly higher scores of depression, anxiety and stress were observed in the students compared to the different groups of employees. Specifically, $60.31 \%$ of the students and $45.07 \%$ of the faculty members presented medium to high scores [29], which corroborates our study, where students' scores were higher for anxiety, stress and fear.

Another study that has data similar to our findings shows the student status significantly associated with higher IES-R ( $\mathrm{B}=0.20,95 \% \mathrm{CI}: 0.05$ to 0.35$)$, DASS stress subscale $(B=0.11,95 \% C I: 0.02$ to 0.19$)$ and DASS anxiety subscale $(B=$ $0.16,95 \%$ CI: 0.02 to 0.30 ) compared to the employed [30]. This shows that be- 
ing a student is a risk factor for psychological symptoms during the pandemic and being employed is a protective factor, findings also shown in our study.

Social support can be a key part in confronting the pandemic. It should be given especially to those most vulnerable to the social and psychological impacts of the pandemic. Grey et al. (2020) demonstrated this in their study, where individuals who experienced self-isolation had significantly higher rates of depression, irritability and loneliness compared to those who were not isolate. The risk for high levels of depression symptoms was $63 \%$ lower in individuals who reported higher levels of social support compared to those with low perceived social support. Similarly, those with high social support had a 52\% lower risk for poor sleep quality compared to those with low social support [31].

At last, it is relevant to mention that this study has some limitations. First, although the participants were people for any region of Brazil, this survey should not be taken as a national sample; secondly, as most of the respondents had an incomplete or complete college degree, it does not reflect most of the Brazilian population.

\section{Conclusion}

The fact that the COVID-19 pandemic affects the students' and unemployed population mental health highlights the urgent need to understand these challenges and concerns in order to promote the development of lines of action and public health responses that will support university students and unemployed population during this difficult time. To do so, it is necessary to conduct researches to understand clearly the relationship between the type of work or occupation and its behaviors facing the various phases of the outbreak and the changes it causes in mental health over time. Public mental health interventions should be formally integrated into public health preparedness and emergency response plans.

\section{Conflicts of Interest}

The authors declare no conflicts of interest regarding the publication of this paper.

\section{References}

[1] Esakandari, H., Nabi-Afjadi, M., Fakkari-Afjadi, J., Farahmandian, N., Miresmaeili, S.M. and Bahreini, E. (2020) A Comprehensive Review of COVID-19 Characteristics. Biological Procedures Online, 22, Article No. 19. https://doi.org/10.1186/s12575-020-00128-2

[2] Bohn, M.K., Hall, A., Sepiashvili, L., Jung, B., Steele, S. and Adeli, K. (2020) Pathophysiology of COVID-19: Mechanisms Underlying Disease Severity and Progression. Physiology (Bethesda, Md.), 35, 288-301. https://doi.org/10.1152/physiol.00019.2020

[3] Satici, B., Gocet-Tekin, E., Deniz, M.E. and Satici, S.A. (2020) Adaptation of the Fear of COVID-19 Scale: Its Association with Psychological Distress and Life Satis- 
faction in Turkey. International Journal of Mental Health and Addiction, 1-9. https://doi.org/10.1007/s11469-020-00294-0

[4] Abad, A., da Silva, J.A., das Neves Braga, J.V.Z., Medeiros, P., de Freitas, R.L., Coimbra, N.C. and da Silva, J.A. (2020) Preparing for the COVID-19 Mental Health Crisis in Latin America-Using Early Evidence from Countries That Experienced COVID-19 First. Advances in Infectious Diseases, 10, 40-44. https://doi.org/10.4236/aid.2020.103005

[5] Sahu, P. (2020) Closure of Universities Due to Coronavirus Disease 2019 (COVID-19): Impact on Education and Mental Health of Students and Academic Staff. Cureus, 12, e7541. https://doi.org/10.7759/cureus.7541

[6] UNESCO (2020) COVID-19 Educational Disruption and Response. https://en.unesco.org/themes/education-emergencies/coronavirus-school-closures

[7] Praun, L. (2020) The Spiral of Destruction: Neoliberal Legacy, Pandemic and Precarization of Work. Trabalho, Educação e Saúde, 18, e00297129. https://doi.org/10.1590/1981-7746-sol00297

[8] Crayne, M.P. (2020) The Traumatic Impact of Job Loss and Job Search in the Aftermath of COVID-19. Psychological Trauma: Theory, Research, Practice and Policy, 12, S180-S182. https://doi.org/10.1037/tra0000852

[9] Martins, N.H.S.P., Salvador, D.F. and Luz, M.R.M.P. (2020) Teacher's Malaise in Discussions about Teaching Nutrition: Speeches of Basic Education Teachers in Virtual Forums. Trabalho, Educação e Saúde, 18, e00286118.

https://doi.org/10.1590/1981-7746-sol00286

[10] Pollock, A., Campbell, P., Cheyne, J., Cowie, J., Davis, B., McCallum, J., McGill, K., Elders, A., Hagen, S., McClurg, D., Torrens, C. and Maxwell, M. (2020) Interventions to Support the Resilience and Mental Health of Frontline Health and Social Care Professionals during and after a Disease Outbreak, Epidemic or Pandemic: A Mixed Methods Systematic Review. Cochrane Database of Systematic Reviews, 5, CD013779. https://doi.org/10.1002/14651858.CD013779

[11] Teixeira, L.E.P.P., de Freitas, R.L., Abad, A., da Silva, J.A., Antonelli-Ponti, M., Bastos, S., Mármora, C.H.C., Campos, L.A.M., Paiva, S. and Da Silva, J.A. (2020) Psychological Impacts Related to Stress and Fear during the COVID19 Pandemic: Cardiovascular Diseases, Diabetes and Psychological Disorders as Risk Factors. World Journal of Neuroscience, 10, 191-205. https://doi.org/10.4236/wjns.2020.104019

[12] Qiu, J.Y., Shen, B., Zhao, M., Wang, Z., Xie, B. and Xu, Y.F. (2020) A Nationwide Survey of Psychological Distress among Chinese People in the COVID-19 Epidemic: Implications and Policy Recommendations. General Psychiatry, 33, e100213. https://doi.org/10.1136/gpsych-2020-100213

[13] Maslow, A.H. (1958) A Dynamic Theory of Human Motivation. In: Stacey, C.L. and DeMartino, M., Eds., Understanding Human Motivation, Howard Allen Publishers, 26-47. https://doi.org/10.1037/11305-004

[14] Hagerty, S.L. and Williams, L.M. (2020) The Impact of COVID-19 on Mental Health: The Interactive Roles of Brain Biotypes and Human Connection. Brain, Behavior and Immunity—Health, 5, 100078.

https://doi.org/10.1016/j.bbih.2020.100078

[15] Almeida, W.S., Szwarcwald, C.L., Malta, C.D., Barros, A.M.B., Souza Júnior, P.R.B., Azevedo, L.O., Romero, D., Damacena, G.N., Machado, Í.E., Gomes, C.S., Pina, M.F., Gracie, R., Werneck, A.O. and Silva, D.R.P. (2020) Changes in Brazilians' Socioeconomic and Health Conditions during the COVID-19 Pandemic. Revista Brasileira de Epidemiologia, 23, e200105. https://doi.org/10.1590/1980-549720200105 
[16] Petitta, L., Probst, T.M., Ghezzi, V. and Barbaranelli, C. (2020) Economic Stress, Emotional Contagion and Safety Outcomes: A Cross-Country Study. Work (Reading, Mass.), 66, 421-435. https://doi.org/10.3233/WOR-203182

[17] Guo, Y., Shen, M., Zhang, X., Xiao, Y., Zhao, S., Yin, M., Bu, W., Wang, Y., Chen, X. and Su, J. (2020) Association of Socioeconomic Changes Due to the COVID-19 Pandemic with Health Outcomes in Patients with Skin Diseases: Cross-Sectional Survey Study. Journal of Medical Internet Research, 22, e22288. https://doi.org/10.2196/22288

[18] Ma, Z.F., Zhang, Y., Luo, X., Li, X., Li, Y., Liu, S. and Zhang, Y. (2020) Increased Stressful Impact among General Population in Mainland China amid the COVID-19 Pandemic: A Nationwide Cross-Sectional Study Conducted after Wuhan City's Travel Ban Was Lifted. The International Journal of Social Psychiatry, 66, 770-779. https://doi.org/10.1177/0020764020935489

[19] Sun, S., Song, Z. and Lim, V.K.G. (2013) Dinâmica do processo de procura de emprego: Desenvolvimento e teste de um modelo de moderação mediada. Journal of Applied Psychology, 98, 771-784. https://doi.org/10.1037/a0033606

[20] Mattei, L. and Heinen, V.L. (2020) Impacts of the COVID-19 Crisis on the Brazilian Labor Market. Brazilian Journal of Political Economy, 40, 647-668. https://doi.org/10.1590/0101-31572020-3200

[21] Mrklas, K., Shalaby, R., Hrabok, M., Gusnowski, A., Vuong, W., Surood, S., Urichuk, L., Li, D., Li, X.M., Greenshaw, A.J. and Agyapong, V. (2020) Prevalence of Perceived Stress, Anxiety, Depression, and Obsessive-Compulsive Symptoms in Health Care Workers and Other Workers in Alberta during the COVID-19 Pandemic: Cross-Sectional Survey. JMIR Mental Health, 7, e22408. https://doi.org/10.2196/22408

[22] Shalaby, R., Hrabok, M., Gusnowski, A., Vuong, W., Surood, S., Urichuk, L., Li, D., Li, X.M., Greenshaw, A.J. and Agyapong, V.I.O. (2020) Prevalence of Perceived Stress, Anxiety, Depression, and Obsessive-Compulsive Symptoms in Health Care Workers and Other Workers in Alberta during the COVID-19 Pandemic: Cross-Sectional Survey. JMIR Mental Health, 7, e22408.

https://doi.org/10.2196/22408

[23] UNESCO (2020) UNESCO Futures of Education Commission Urges Planning Ahead against Increased Inequalities in the Aftermath of the Covid-19. UNESCO, Paris.

https://en.unesco.org/news/unesco-futures-education-commission-urges-planningahead-against-increased-inequalities

[24] Thomas, M. and Rogers, C. (2020) Education, the Science of Learning, and the COVID-19 Crisis. Prospects, 1-4. https://doi.org/10.1007/s11125-020-09468-Z

[25] Rotenstein, L.S., Ramos, M.A., Torre, M., Segal, J.B., Peluso, M.J., Guille, C., Sen, S. and Mata, D.A. (2016) Prevalence of Depression, Depressive Symptoms, and Suicidal Ideation among Medical Students: A Systematic Review and Meta-Analysis. JAMA, 316, 2214-2236. https://doi.org/10.1001/jama.2016.17324

[26] Sokratous, S., Merkouris, A., Middleton, N. and Karanikola, M. (2014) The Prevalence and Socio-Demographic Correlates of Depressive Symptoms among Cypriot University Students: A Cross-Sectional Descriptive Co-Relational Study. BMC Psychiatry, 14, 235. https://doi.org/10.1186/s12888-014-0235-6

[27] Zhai, Y. and Du, X. (2020) Addressing Collegiate Mental Health amid COVID-19 Pandemic. Psychiatry Research, 288, Article ID: 113003.

https://doi.org/10.1016/j.psychres.2020.113003 
[28] Odriozola-González, P., Planchuelo-Gómez, Á., Irurtia, M.J. and de Luis-García, R. (2020) Psychological Effects of the COVID-19 Outbreak and Lockdown among Students and Workers of a Spanish University. Psychiatry Research, 290, Article ID: 113108. https://doi.org/10.1016/j.psychres.2020.113108

[29] Wang, C., Pan, R., Wan, X., Tan, Y., Xu, L., Ho, C.S. and Ho, R.C. (2020) Immediate Psychological Responses and Associated Factors during the Initial Stage of the 2019 Coronavirus Disease (COVID-19) Epidemic among the General Population in China. International Journal of Environmental Research and Public Health, 17, 1729. https://doi.org/10.3390/ijerph17051729

[30] Grey, I., Arora, T., Thomas, J., Saneh, A., Tohme, P. and Abi-Habib, R. (2020) The Role of Perceived Social Support on Depression and Sleep during the COVID-19 Pandemic. Psychiatry Research, 293, Article ID: 113452.

https://doi.org/10.1016/j.psychres.2020.113452

[31] Dong, L. and Bouey, J. (2020) Public Mental Health Crisis during COVID-19 Pandemic, China. Emerging Infectious Diseases, 26, 1616-1618.

https://doi.org/10.3201/eid2607.200407 


\section{Appendices}

\section{Appendix 1: COVID-19 Peritraumatic Distress Index (CPDI).}

Please indicate how often, in the last week, the activities listed below have taken place. To do this, circle the response category (from 0 to 4 ) that you think is most appropriate for you.






\section{Appendix 2: Fear of COVID-19 Scale}

The emergence of COVID-19 and its consequences has led to fears, concerns and anxiety to individuals around the world. In this study, we are interested in investigating the fear associated with the rate and means of transmission (fast and invisible) of the corona virus, as well as its morbidity and mortality.

Please, for this, after reading each statement, circle a numerical category that best indicates your level of agreement with the statement.

\begin{tabular}{|c|c|c|c|c|c|}
\hline AFFIRMATIONS & $\begin{array}{l}\text { Strongly } \\
\text { disagree }\end{array}$ & disagree & $\begin{array}{l}\text { Neither agree } \\
\text { nor disagree }\end{array}$ & I agree & $\begin{array}{c}\text { Strongly } \\
\text { agree }\end{array}$ \\
\hline 1. I am most afraid of coronavirus-19. & 1 & 2 & 3 & 4 & 5 \\
\hline 2. It makes me uncomfortable to think about the coronavirus- 19 . & 1 & 2 & 3 & 4 & 5 \\
\hline 3. My hands become clammy when I think about coronavirus- 19 . & 1 & 2 & 3 & 4 & 5 \\
\hline 4. I am afraid of losing my life because of coronavirus- 19 . & 1 & 2 & 3 & 4 & 5 \\
\hline $\begin{array}{l}\text { 5. When watching news and stories about coronavirus- } 19 \text { on social media, I } \\
\text { become nervous and anxious. }\end{array}$ & 1 & 2 & 3 & 4 & 5 \\
\hline 6. I cannot sleep because I'm worrying about getting coronavirus- 19 . & 1 & 2 & 3 & 4 & 5 \\
\hline 7. My heart races or palpitates when I think about getting coronavirus-19. & 1 & 2 & 3 & 4 & 5 \\
\hline
\end{tabular}

